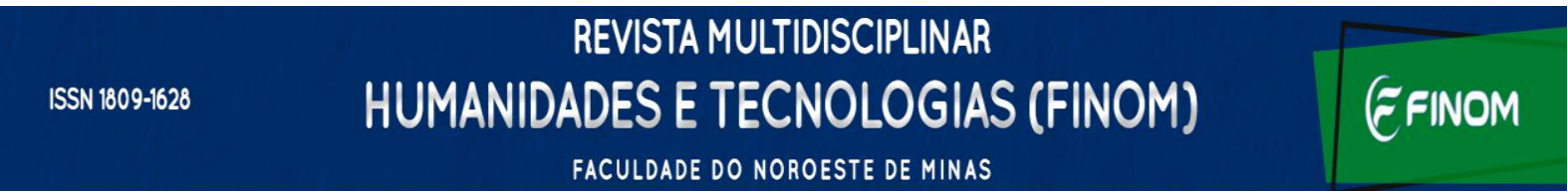

\title{
Competência e habilidades inerentes às atividades de Coordenação de Curso em Instituições de Ensino Superior
}

\section{Competence and skills inherent in Course Coordination activities in Higher}

\section{Education Institutions}

\author{
Ananere da Silva Cruz ${ }^{1}$ \\ Ariane Cristina Silva ${ }^{2}$ \\ Daniel Knebel Baggio ${ }^{3}$ \\ Maria Margarete Baccin Brizola ${ }^{4}$ \\ Nelson José Thesing ${ }^{5}$
}

Resumo: O presente estudo tem como objetivo conhecer as competências individuais, técnicas e comportamentais consideradas relevantes nas atividades de coordenação de curso. $\mathrm{O}$ estudo conta com a pesquisa descritiva, qualitativa, de natureza, como aplicada. O conjunto dos achados permitem identificar que as características de liderança e relacionamento interpessoal, para os coordenadores são características muito importantes para o exercício da função. Os coordenadores consideram a boa comunicação com todos os atores, como sendo muito importante, bem como, atuar no ensino, na evasão, na inadimplência. Ainda, destacaram a importância do Projeto Pedagógico de Curso, o Exame Nacional de Desempenho de Estudantes, a Política de Acompanhamento de Egressos, o que desafia o

\footnotetext{
${ }^{1}$ Mestrado em Desenvolvimento Regional, Universidade Regional do Noroeste do Estado do Rio Grande do Sul, ananere.cruz@sou.unijui.edu.br

${ }^{2}$ Mestrado em Desenvolvimento Regional, Universidade Regional do Noroeste do Estado do Rio Grande do Sul, ariane.borges@sou.unijui.edu.br

${ }^{3}$ Mestrado em Desenvolvimento Regional, Universidade Regional do Noroeste do Estado do Rio Grande do Sul, baggiod@unijui.edu.br

${ }^{4}$ Mestrado em Desenvolvimento Regional, Universidade Regional do Noroeste do Estado do Rio Grande do Sul, marga.brizolla@unijui.edu.br

${ }^{5}$ Mestrado em Desenvolvimento Regional, Universidade Regional do Noroeste do Estado do Rio Grande do Sul, nelson.thesing@unijui.edu.br
}

Recebido em 23/01/2022

Aprovado em 10/02/2022

Sistema de Avaliação: Double Blind Review

OPEN ACCESS (1) 


\section{REVISTAMULTIDISCIPLINAR

processo de formação dos coordenadores, para ampliar as competências individuais, técnicas e comportamentais.

Palavras-chaves: Ensino Superior; Gestão Acadêmica; Perfil Profissional; Habilidades e Competências.

Abstract: This study aims to understand the individual, technical and behavioral skills considered relevant in course coordination activities, to manage the functions. To verify this theme, the study relies on descriptive, qualitative, nature and applied research. The set of findings allow us to identify that the characteristics of leadership and interpersonal relationships, for the coordinators, are very important characteristics for the exercise of the function. The coordinators consider good communication with all actors to be very important, as well as acting on education, evasion, default. They also highlighted the importance of the Pedagogical Course Project, the National Student Performance Examination, the Graduate Monitoring Policy, which challenges the process of training coordinators, to expand individual, technical and behavioral skills.

Keywords: Higher Education; Academic Management; Professional Profile, Skills and Competences.

\section{Introdução}

O coordenador de curso de graduação surgiu no ensino superior com a reforma universitária nas décadas de 1960 e 1970, que instituiu um conjunto de normas que modificaram o ensino superior no Brasil. Entre as mudanças, foi introduzido o regime departamental, em substituição aos conselhos administrativos e congregações, cursos semestrais e sistemas de crédito em substituição aos anuais, vestibulares unificados e classificatórios no lugar de eliminatórios, aumento de vagas principalmente nas instituições privadas e instituiu o regime de pós-graduação (HISDORF, 2003)

Assim, tem-se presente que as funções do coordenador de curso, por muitos anos, tiveram o papel de mediador, entre alunos, professores e direção. O cargo era ocupado por um professor ou pesquisador designado pela Instituição de Ensino Superior (IES) para coordenar, acompanhar e avaliar as atividades acadêmicas do curso. Normalmente, para as atividades de coordenador de curso, não era exigido experiência na área de gestão, uma vez que, na sua grande maioria, a atividade deste profissional, estava completamente voltada para docência.

No entanto, para Aragão et. al. (2017), a partir da Lei n 9.394/96 - Lei de Diretrizes e Bases da Educação (LDB), editada em dezembro de 1996, revogou a legislação da Reforma 


\section{REVISTAMULTIDISCIPLINAR \\ ISSN 1809-1628 HUMANIDADES E TECNOLOGIAS (FINOM)}

Universitária de 1968. Assim, com a nova LDB, o coordenador passou assumiu um papel fundamental na gestão dos cursos de graduação das Instituições do Ensino Superior Brasileiras. Para além, a nova legislação, em seu Artigo 43 trata, especificamente, da Educação Superior e suas finalidades.

Atenta-se para a Lei $\mathrm{n}^{\circ} 10.861$, de 14 de abril de 2004 - Lei do Sinaes, que normatizou o Sistema Nacional de Avaliação da Educação Superior (Sinaes), apresenta também novos desafios ao coordenador de curso, ao introduzir uma avaliação nas Instituições de Educação Superior, especialmente nos cursos de graduação e no desempenho acadêmico de seus estudantes. Desta forma, a Lei do Sinaes consolidou, definitivamente, a necessidade de atuação ampla e abrangente do coordenador de curso, pelo seu envolvimento com as questões acadêmicas, administrativas da instituição de ensino e do curso de graduação.

Já nos estudos de Marcon (2011), é fundamental que as organizações de Ensino Superior desenvolvam a capacidade de atuar, dos seus docentes coordenadores, com um grau de perfeição elevada, para praticar uma gestão que valorize as decisões a partir de planejamentos, tendo como finalidade maior o foco nas atividades-fim da organização. Para Marquezin et al (2008), apresentam a complexa e fascinante atuação do coordenador de curso, nas Instituições de Ensino Superior, tendo um papel de agregador, de integração, de responsabilidade para conquistar a melhoria do ensino superior. Deste modo, Delpino et al, propõem a ampliação do debate sobre papel do coordenador de curso superior, especialmente no processo de manutenção e desenvolvimento de práticas pedagógicas que garantam a qualidade dos cursos oferecidos.

Assim, diante da relevância da atuação do coordenador de curso, como diferencial de competitividade para IES, objetivou-se este estudo, para conhecer as competências individuais, técnicas e comportamentais consideradas relevantes nas atividades do coordenador de curso para realizar suas funções, o que oportuniza a estruturação do artigo em cinco partes, para além desta Introdução, o Referencial Teórico, Metodologia da Pesquisa, Discussão dos Resultados e as Considerações Finais.

\section{Referencial teórico}




\section{REVISTAMULTIDISCIPLINAR \\ ISSN 1809-1628 \\ HUMANIDADES E TECNOLOGIAS (FINOM)}

Parte-se da década de 1980, conhecida como a era da informação, época marcada por grandes transformações, principalmente no que se refere às comunicações, mudaram-se os parâmetros de comportamento de toda uma sociedade. O surgimento de um mercado globalizado acarretou profundas modificações na ordem social, econômica, política e ambiental de uma nação, já que as informações passaram a fazer parte de um mundo globalizado, interferindo não exatamente onde ocorre, mas em diferentes partes do planeta, bem como no mundo acadêmico.

Desta forma, os aportes teóricos-metodológicos receberam fortes influências do conjunto de mudanças que aconteceram no cotidiano em nível mundial, o que proporcionou mudança no ensino superior no Brasil, porém, segue passando por um período de redefinição das suas funções, remodelando sua atuação e, consequentemente, de todos os agentes que fazem parte de seu contexto (PORTO; RÉGNIER 2003). Assim, essas mudanças transbordam em todos os ambientes acadêmicos, desenvolvem um novo paradigma, o da profissionalização das atividades, exigindo dos coordenadores novas posturas, um posicionamento inovador, em todos os segmentos da IES, ao serem convocados a colaborar na construção de resultados positivos.

Portanto, novas configurações são estabelecidas para o coordenador de curso, se em um passado recente, as atividades acadêmicas absorviam quase que a totalidade de suas funções, hoje este profissional se vê tendo que desenvolver novas competências para se adaptar às demandas sócio educacionais, incertezas de mercado e ainda inseguranças e expectativas tanto dos discentes quanto dos docentes. Para Marcon (2011), coordenar um curso de graduação numa organização de Ensino Superior é uma tarefa que requer comportamentos profissionais específicos de quem tem a responsabilidade pelas atribuições do cargo.

Consequentemente, o coordenador para além das exigências apontadas pelo Ministério da Educação (MEC), as IES buscam um perfil profissional, com características de liderança, trabalho em equipe, que seja organizado e tenha habilidades políticas, humanas e conceituais. A própria palavra "coordenação" traz consigo um significado restrito para esta função, que tem se tornado uma multitarefa. Assim, tem-se presente a complexidade do campo de atuação dos coordenadores de IES, no contexto brasileiro e, as exigências evidenciadas apontam a necessidade de construir um profissional competente, ao analisar a 


\section{REVISTAMULTIDISCIPLINAR \\ ISSN 1809-1628 HUMANIDADES E TECNOLOGIAS (FINOM)}

formação dessa desta categoria profissional e a sua atuação frente à gestão dos cursos (MANÇO 2016)

Assevera Franco (2003), tanto no passado como no presente, ainda não se chegou a um denominador comum quanto às funções, às responsabilidades, às atribuições e aos encargos do coordenador de curso. Coordenar um curso é muito mais do que uma simples execução de tarefas burocráticas e rotineiras. Para Lamcobe (2015), coordenar é equilibrar, sincronizar e integrar as ações das pessoas e as atividades das unidades organizacionais, de acordo com certa ordem e método, para assegurar seu desenvolvimento harmônico.

Desta forma, ao não perder de vista às mudanças constantes exigidas no Projeto Pedagógico do curso, cabe ao coordenador, buscar decisões estratégias de extrema importância para o bom andamento das atividades do curso. O que pode significar a busca de uma visão sistêmica de todas as áreas que envolvem o departamento, suas relações de interdependência, identificando as potencialidades e fragilidades do ambiente interno e externo. Diante disso, Manço (2016), destaca frente às inúmeras funções atribuídas ao coordenador de cursos de IES privadas, a responsabilidade em desenvolver a dinâmica do curso, conduzindo-o na perspectiva de oferecer presteza de informações e conhecimentos que proporcionem a formação do profissional de maneira ampla.

Assim, vários profissionais que pretendem atuar na área da coordenação, não fazem ideia da complexidade que envolve o mesmo. Significa, as relações interpessoais com docentes, discentes e técnicos administrativos sejam desenvolvidas em um ambiente de confiança, de troca de informações e conhecimento. Diante disso, os principais agentes responsáveis por fazer o intercâmbio entre a comunidade acadêmica e o público externo, aponta um novo horizonte do coordenador. Não basta preencher requisitos legais para o exercício da profissão, é necessário desenvolver um bom relacionamento no ambiente de trabalho e fora dele. Além dos fatores econômicos, pedagógicos e administrativos, as relações humanas e a forma como elas são desenvolvidas contribuem para o crescimento institucional.

No entender de Ferrari e Nascimento (2014), para ser um coordenador gestor, o importante é alcançar resultados que poderiam ser explicitados como: conceitos positivos nas avaliações; baixos índices de evasão; elevados índices para número de ingressantes; e um excelente nível de relacionamento entre o coordenador, professores, alunos e gestores da IES. 


\section{ISSN $1809-1628$ \\ REVISTA MULTIDISCIPLINAR \\ HUMANIDADES E TECNOLOGIAS (FINOM)}

EFINOM

FACULDADE DO NOROESTE DE MINAS

Já Franco (2003), distribuiu as funções dos coordenadores de curso em quatro áreas distintas: funções políticas, funções gerenciais, funções acadêmicas e funções institucionais. Deste modo, com base nestas quatro funções, buscou-se analisar quais competências e habilidades são inerentes ao cargo de coordenador de curso de graduação.

Assim, busca-se descortinar a função política que não se restringe unicamente a atividade exercida por políticos. Para Aristóteles (2019), o homem é um "animal político", pois somente ele possui a linguagem e esta é o fundamento da comunicação entre os seres humanos. Política é toda e qualquer forma de se relacionar. Ser político, basicamente, significa aquele que se relaciona bem com as outras pessoas, que é participativo, que se comunica com facilidade, que é capaz de construir argumentos para convencer as pessoas a mudar de ideia. Que desenvolva o espirito de liderança, para exercer a função de coordenador de curso, que amplia a rede de relacionamentos, que lhe permita tramitar entre todas as partes isoladas do processo, com objetivo de ampliar transparência na área de gestão.

Portanto, a rede de relacionamento, papel do coordenador, atualmente, passa por constantes mudanças. A todo instante tem-se novas exigências, sejam da legislação em vigor, sejam do mercado de trabalho ou do cliente. Isso requer que o coordenador de curso esteja sempre em processo de atualização. O coordenador precisa ser um eterno estudioso, um excelente professor, para que tenha condições de auxiliar seus docentes e discentes nas questões que se apresentam diariamente no mundo acadêmico.

Logo, em Hunter (2004), encontra-se o papel de liderança como uma habilidade de influenciar pessoas para trabalharem entusiasticamente visando atingir os objetivos identificados como sendo para o bem comum. Desta forma, o coordenador de curso necessita ser um líder para conduzir discentes, docentes e colegas de trabalho, numa relação harmoniosa em que não somente o fator hierárquico está envolvido, mas, todo contexto que engloba a construção de uma cadeia de conhecimentos, estímulos e experiências, estabelecendo desta forma, seu estilo de liderança, e sendo reconhecido como um líder capaz de promover mudanças significativas na sua área de atuação. Exercer e construir uma liderança eficaz, onde docentes e discentes são convidados a fazerem parte, na busca pela maximização dos resultados, na sua área de atuação, faz-se necessário cultivar o sentimento de ser e pertencer a um trabalhado de equipe. 


\section{REVISTAMULTIDISCIPLINAR \\ ISSN 1809-1628 HUMANIDADES E TECNOLOGIAS (FINOM)}

Segundo Dornelas (2003) as definições para empreendedorismo são várias, mas sua essência se resume em fazer diferente, empregar recursos disponíveis de forma criativa, assumir riscos calculados, buscar oportunidades e inovar. O empreendedor é um inovador de contextos. As atitudes do empreendedor são construtivas. Possuem entusiasmo e bom humor. Para ele não existem apenas problemas, mas problemas e soluções, assim líderes empreendedores são criativos, estabelecem metas e objetivos bem definidos, são observadores, competitivos e criteriosos, conseguindo enxergar oportunidades, (BAGGIO; BAGGIO 2017). O que também não deixa de ser um novo requisito para função de coordenador.

Cada curso tem a dinâmica, a ousadia e o perfil do seu coordenador. Atuando em mercados concorrentes, o curso oferecido por determinada IES é o mesmo ofertado por outras instituições, e muitas vezes em pequenas distâncias geográficas. Certamente, o curso que estiver sendo conduzido por um líder com espírito empreendedor conseguirá visualizar as melhores oportunidades do seu nicho de atuação, conseguindo antecipar decisões, que o destacará frente aos seus principais concorrentes. No entender de Franco (2003), o coordenador de curso nunca alcançará o pleno exercício de todas as funções políticas, mas deverá procurar abrangê-las ao máximo, de sorte que seja reconhecido na instituição e fora dela, na função que exerce.

Para conhecer uma outra função do coordenador de curso definida por Franco (2003) como função gerencial, se faz necessário entender as IES enquanto empresas geradoras de emprego, renda e prestadoras de serviços. Para Benati (gestão educacional) o grande desafio do sistema educacional, nos dias de hoje, é o tratamento da escola como uma empresa prestadora de serviço.

Ao analisar os números de matrícula divulgados pelo Instituto Nacional de Estudos e Pesquisas Educacionais “Anísio Teixeira” (INEP 2021) nos resultados do Censo da Educação Superior do ano de 2019, a rede privada detém, atualmente, 84,6\% da oferta de educação superior do país. Então, é relevante considerar a importância da manutenção e sustentação das IES como empresas que contribuem, consideravelmente, para o desenvolvimento socioeconômico do Brasil.

Não deixando de lado o contexto social da região em que atua, as políticas institucionais devem estar bem definidas para que a IES possa ser reconhecida como um 


\section{REVISTAMULTIDISCIPLINAR \\ ISSN 1809-1628 HUMANIDADES E TECNOLOGIAS (FINOM)}

educandário que integra e se preocupa com as questões sociais, econômicas, políticas e ambientais. As empresas são constituídas por sistemas complexos. Devido à complexidade deste sistema, existe a divisão das tarefas, divisão de níveis hierárquicos e a fragmentação do todo em pequenas partes que interagem entre si, com a mesma finalidade, atingir os diversos objetivos previamente definidos pela IES.

Existem vários setores que necessitam estar interligadas com a coordenação de curso. Dentre eles citam-se como exemplo, núcleos de apoio às atividades acadêmicas, secretaria, setor financeiro e comunidade local. Para que seja possível fazer a conexão de todas as partes que compõem este sistema que está em torno do coordenador de cursos é necessário que este profissional esteja atuando em diferentes frentes de trabalho, que são nomeadas por Franco (2003) como funções gerenciais.

A função gerencial é atípica, não existe uma definição exata para ela, é extremamente generalista. Existe um leque grande de atividades que estão embutidas nesta função e que, certamente, não estão minuciosamente detalhadas no manual de descrição do cargo de coordenador. De acordo com Silva (2008) a administração de nível médio é conhecida em muitas empresas como gerência de departamento ou gerência de setor. Diferentemente dos gerentes de primeiro nível ou supervisão, os gerentes de nível médio planejam, organizam, dirigem e controlam outras atividades gerenciais.

O profissional que assume a coordenação de curso se torna um referencial para discentes e docentes. Conhecer os processos que envolvem a vida acadêmica deste público se torna uma obrigação ou exigência. A sua participação nas ações e eventos desenvolvidos pela IES, bem como, conselhos, associações e comitês pertencentes à sociedade civil organizada torna-se inerente ao trabalho do coordenador de curso.

O Projeto Pedagógico de Curso (PPC) é o instrumento de concepção do ensino e aprendizagem do curso, ele apresenta a concepção e estrutura do curso, o currículo, os procedimentos de avaliação do ensino e aprendizagem, instrumentos normativos de apoio (composição do colegiado e núcleos, procedimentos de estágio, dentre outros). A Atualização do PPC é uma atividade que nunca estará finalizada, ele demandará adequação, reelaboração, implementação e avaliação constantes. A construção contínua do PPC demandará uma atenção especial por parte do coordenador. 


\section{REVISTAMULTIDISCIPLINAR \\ ISSN 1809-1628 HUMANIDADES E TECNOLOGIAS (FINOM)}

Dois indicadores de extrema importância e que estão nas pautas de análises e acompanhamento dos gestores educacionais são a evasão e a inadimplência. A evasão e a inadimplência influenciam e comprometem a sustentabilidade financeira das instituições, podendo interferir na capacidade de manutenção e investimento em infraestrutura física, tecnológica e de pessoal, que são imprescindíveis para a existência de uma IES.

No Brasil, segundo pesquisa divulgada pelo Sindicato das Instituições de Ensino Superior Privado (SEMESP, 2019), o índice de evasão nas instituições privadas é de 3,2\% nos cursos presenciais e 5,56\% nos cursos a distância (EaD). A evasão deve-se a três fatores: decepção com a carreira escolhida, falta de condição financeira e falta de condição para acompanhar o ritmo das aulas, uma vez que, a grande maioria deste público trabalha durante o dia e estuda à noite.

O coordenador precisa conhecer e acompanhar o índice de evasão no curso por ele coordenado, pois isso permitirá conhecer algumas fragilidades e potencialidades do curso por ele coordenado. A meta de redução do índice de evasão é definida pela política de gestão de cada IES e compete ao coordenador de curso, para garantir a sustentabilidade e, por conseguinte, a sobrevivência do curso, se comprometer em atingir a meta de redução de evasão estabelecida pelos gestores institucionais.

Para Franco (2003), o coordenador deve ser responsável pela adimplência contratual dos alunos de seu curso. É indiscutível que tal matéria sempre é encarada com alguma reserva nas Instituições de Ensino Superior (IES), especialmente pelos integrantes da área acadêmica. No país, o índice de inadimplência é um fator que muda significativamente de uma região para outra, ou mesmo de um curso para outro, mas ainda segundo dados do Sindicato das Instituições de Ensino Superior Privado (SEMESP 2020) a inadimplência no ensino superior atingiu índices de $15,8 \%$ para cursos presenciais e 19,6\% para cursos a distância, no ano de 2020.

O aumento da inadimplência compromete de forma geral o funcionamento da IES, sua capacidade de investimento em infraestrutura física, recursos tecnológicos e até mesmo sua manutenção, sua expansão e sustentação financeira, uma vez que IES depende, prioritariamente, dos recursos financeiros advindos do pagamento dos valores referentes à prestação dos serviços educacionais por parte dos seus acadêmicos. 


\section{REVISTAMULTIDISCIPLINAR \\ ISSN 1809-1628 HUMANIDADES E TECNOLOGIAS (FINOM)}

Além de atuar, de acordo com as políticas estabelecidas pela IES, no controle e redução da inadimplência relacionados ao curso por ele coordenado, o coordenador precisa e deve priorizar a busca por fontes alternativas de recursos que viabilizem a manutenção e sustentação do seu curso. Existem vários laboratórios na IES que comportam a prestação de serviços para comunidade local e regional, muitas vezes sendo a única com capacidade e equipamentos disponíveis para oferta dos serviços de interesse da sociedade. A utilização da infraestrutura física e tecnológica, que em alguns casos permanece ociosa na maior parte do tempo, é um nicho a ser explorado a fim de maximizar a utilização dos laboratórios e serviços que a IES pode prestar.

A cada dia mais as instituições têm buscado diversificar seu portfólio de serviços com objetivo de ampliar seu leque de atuação e assim atender às demandas do mercado e da região em que está inserida. Desta forma o envolvimento e atuação nas funções gerenciais irá permitir que o coordenador tenha a dimensão e amplitude de sua área de atuação, contribuindo de forma efetiva para condução da próxima função definida por Franco (2003), que é a função acadêmica.

As funções intituladas acadêmicas são melhor compreendidas pelos coordenadores de curso, pois normalmente este profissional já está familiarizado com essas atribuições e já as considera como sendo inerentes a sua atuação. Na realidade, quando se refere à atividade de coordenação de curso faz-se, imediatamente, a assimilação com funções meramente acadêmicas o que, na atualidade, não se concretiza no cotidiano do trabalho do coordenador.

O ensino, a pesquisa e extensão são os três pilares do ensino superior brasileiro. São sobre esses pilares que se desenvolvem as atividades de uma instituição de ensino superior. Manter a articulação deste tripé é de suma importância para que a IES possa cumprir a sua função junto à sociedade.

O coordenador deve estimular o desenvolvimento da iniciação científica e da pesquisa entre professores e alunos (FRANCO, 2003). Algo do que mais reclamam os estudantes ao responderem anualmente o Questionário do ENADE?) É que inexiste pesquisa nas instituições que frequentam. O curso precisa manter o seu nível de produção, o docente precisa produzir e obviamente o discente deve ser estimulado à produção acadêmica.

O coordenador de curso precisa ser um excelente professor. Deve ser um perfeccionista por natureza, sua vocação para o magistério deve sobrepor às outras aptidões. 


\section{REVISTAMULTIDISCPLLINAR \\ ISSN 1809-1628 HUMANIDADES E TECNOLOGIAS (FINOM)}

Se a docência não é um atributo da qual o coordenador possua aderência e competência, ele não terá condições de sugerir e contribuir com a melhoria contínua dos processos de ensino e aprendizagem dos que trabalham sob sua gestão. Enricone (2001) entende que o professor que assume a postura transformadora, trata seus alunos como sujeitos críticos, questiona a forma de construção de conhecimento, utiliza o diálogo como prática de seu ensino e, nesse diálogo, não apenas investiga e reconhece, mas também respeita a subjetividade de cada um.

A questão pedagógica e mais especificamente o processo de ensino-aprendizagem precisa estar em discussão a cada início de semestre, conhecer e acompanhar as atividades complementares, que tem como objetivo enriquecer o processo de ensino e aprendizagem, estimular os seus discentes à prática de estudos independentes, de atualização profissional, da pesquisa, iniciação científica, da monitoria e dos projetos de extensão. O aluno deve ser estimulado a produzir trabalhos acadêmicos que propiciem o desenvolvimento de competências que são inerentes a sua área de formação.

A partir da implantação da Lei do Sinaes, o Exame Nacional de Desempenho dos Estudantes (Enade) passou a avaliar o rendimento dos concluintes dos cursos de graduação em relação aos conteúdos programáticos previstos nas diretrizes curriculares nacionais dos cursos, o desenvolvimento de competências e habilidades necessárias ao aprofundamento da formação geral e profissional, e o nível de atualização dos estudantes com relação à realidade brasileira e mundial. O resultado deste indicador passou a ser um referencial para a sociedade, destacando-se o índice desenvolvido para atestar o grau de conhecimento e competência adquiridos pelos alunos, durante a realização do curso de graduação.

O Enade integra o Sistema Nacional de Avaliação da Educação Superior (SINAES), composto também pela avaliação de cursos de graduação e pela avaliação institucional. Juntos eles formam o tripé avaliativo que permite conhecer a qualidade dos cursos e instituições de educação superior brasileiras. Os resultados do Enade, aliados às respostas do Questionário do Estudante, são insumos para o cálculo dos Indicadores de Qualidade da Educação Superior. Devido à importância deste indicador para o curso e para a IES.

A última função descrita por Franco (2003) é a função institucional. Constata-se que as funções institucionais estão alocadas em todos os tópicos que são abordados neste estudo. A proposta de Franco (2003) é que seja realizada uma introspecção dentro do curso 


\section{REVISTAMULTIDISCPLLINAR \\ ISSN 1809-1628 HUMANIDADES E TECNOLOGIAS (FINOM)}

coordenado e das várias questões legais que envolvem o ensino superior e, consequentemente, as atividades do coordenador de curso.

O Plano de Desenvolvimento Institucional (PDI) é o documento que identifica a Instituição de Ensino Superior (IES), no que diz respeito a sua filosofia de trabalho, à missão a que se propõe, às diretrizes pedagógicas que orientam suas ações, a sua estrutura organizacional e às atividades acadêmicas que desenvolve e/ou que pretende desenvolver (MEC, 2009). Ao estabelecer seu PDI a IES estabelece metas de curto e longo prazos a serem alcançadas, assim como indicadores que possibilitam o acompanhamento das ações decorrentes de seu planejamento. Para que o processo de melhoria contínua do Projeto Pedagógico do Curso (PPC) seja bem-sucedido é imprescindível que o coordenador de curso conheça o PDI da IES.

Um curso de graduação passa por um processo contínuo de avaliação desde o momento da sua autorização. Os ciclos regulatórios de reconhecimento, auto avaliação, ENADE e renovação de reconhecimento precisam de acompanhamento, gestão e cumprimento de prazos, portanto devem fazer parte da agenda de trabalho do coordenador. O coordenador do curso deve conhecer e informar quais são os requisitos mínimos de qualidade exigidos pelo Ministério da Educação (MEC) para sua área de atuação e ele sim é quem deve transmitir a informação a seus docentes, discentes, colegiado, núcleos pedagógicos e demais setores envolvidos no processo. A sua equipe pedagógica, professores e núcleos devem trabalhar em sintonia para propor ao longo do período letivo um trabalho que vise corrigir os erros e maximizar os acertos, buscando assim resultados positivos.

A Lei do Sinaes (Lei n ${ }^{\circ} 10.861$ de 2004) determinou a criação, em cada IES, de uma Comissão Própria de Avaliação, também identificada pela sigla CPA. A CPA é o órgão responsável pela condução do processo de autoavaliação institucional, que tem como objetivo a avaliação da IES de maneira global. É também função do coordenador de curso a conscientização de toda comunidade acadêmica da importância que o processo de autoavaliação institucional, conduzido pela CPA, seja visto como mensurador da qualidade do desempenho da IES, sendo capaz de criar uma cultura de mudança e valorização do que é produzido pela própria comunidade acadêmica. $\mathrm{O}$ coordenador deve integrar as suas rotinas as atividades desempenhadas pela CPA, como forma de incentivo à contribuição de todos na busca pela melhoria contínua das rotinas e processos que norteiam as IES e seus cursos. 


\section{REVISTAMULTIDISCIPLINAR \\ ISSN 1809-1628 HUMANIDADES E TECNOLOGIAS (FINOM)}

O acompanhamento dos egressos é fator importante como subsídios para constante atualização do PPC e também para o sucesso do curso de graduação. A escolha por um curso de graduação, por parte dos candidatos, perpassa também pelo quão bem-sucedidos são os egressos do curso de interesse. Por isso, o coordenador de curso deve estabelecer uma comunicação eficaz com o egresso, coletar dados e informações, com o intuito de interagir, apoiar e fomentar sua entrada no mercado de trabalho, além de incentivar a sua formação continuada. Para isso, o coordenador precisa estar envolvido, por exemplo, com as ações desenvolvidas dos núcleos de estágios e carreiras, que são responsáveis por estabelecer o elo entre os estudantes e o mercado de trabalho. O relacionamento com a comunidade local é indispensável para entender quais são as demandas locais e em que mercado seu egresso será inserido. Constata-se então que é neste contexto de exigências e amplitude de atuação que o coordenador de curso está inserido, envolvimento em várias funções muito além dos saberes construídos em sua formação e exercício da docência, respondendo tanto pedagógica quanto administrativamente pelo curso que coordena.

Delfino et al (2009), enfatiza para que o profissional alcance o perfil desejado pelas Instituições ele também precisa de uma estrutura de suporte, que por sua vez, depende de uma série de fatores: disponibilidade de informações, carga horária adequada, remuneração condizente e definição clara das competências.

De acordo com Ferrari e Nascimento (2014), ainda são poucos os estudos que analisam o perfil desses profissionais. Mas se tornam cada vez mais importantes à medida que as IES se consolidam no cenário nacional e a qualidade do ensino oferecido é cada vez mais exigida. E essa melhoria da educação superior pode ser promovida à medida que tais estudos apontem, às IES, estratégias para a melhor capacitação de seus gestores.

Aragão et al (2017), em um trabalho no qual estudou os desafios do coordenador na gestão de cursos de graduação em uma universidade pública e privada propôs a discussão sobre o papel, o perfil e os desafios do coordenador de curso como gestor acadêmico, identificando modelos de gestão em uma universidade pública e privada. Ele evidenciou a importância do coordenador de curso de graduação após as recentes políticas públicas para o ensino superior brasileiro, e ainda que não há bibliografia específica que aborde a complexidade do trabalho do coordenador, enquanto gestor educacional. 


\section{REVISTAMULTIDISCIPLINAR \\ ISSN 1809-1628 \\ HUMANIDADES E TECNOLOGIAS (FINOM)}

Soboya et al (2020), em um estudo em que aborda os novos desafios para coordenadores de cursos de IES privadas no Brasil, buscou identificar as competências necessárias e utilizadas pelos coordenadores de curso no cumprimento de diretrizes estratégicas de uma Instituição Ensino Superior Privada. Uma das constatações deste estudo é de que o papel do coordenador sofreu alterações, fazendo com que evoluíssem as atribuições a sua função, não somente acadêmicos, que são próprios da função, mas ainda de gestão.

Assim, objetivou-se com esse estudo conhecer quais competências individuais, técnicas e comportamentais são consideradas relevantes pelo coordenador de curso, para fazer o gerenciamento de suas funções.

\section{Metodologia}

Em relação aos objetivos trata-se de um estudo descritivo, que para Moraes (2013), se identifica como sendo estudos que buscam especificar as propriedades, as características e os perfis de pessoas, grupos, comunidades, processos, objetos ou qualquer outro fenômeno que se submeta a uma análise. Já quanto aos procedimentos classifica-se como um estudo de campo. Para Gil (2008), o estudo de campo é o aprofundamento de uma realidade específica. É basicamente realizada pela observação direta das atividades do grupo estudado, por entrevistas por pesquisa de campo, orientado por um questionário, que foi aplicado junto aos coordenadores de cursos de graduação em três instituições privadas de ensino superior localizadas no estado de Minas Gerais.

No que refere a abordagem do problema, a pesquisa se caracteriza como qualitativa. Para Knechtel (2014), a pesquisa qualitativa tem por preocupação o ponto de vista do indivíduo: a primeira considera a proximidade do sujeito, por exemplo, por meio da entrevista. Ainda, a pesquisa se classifica, quanto à natureza, como aplicada, apoiada nos ensinamentos de Zamberlan et al. (2014), para gerar conhecimentos, na área da coordenação de curso.

População e amostra 


\section{REVISTAMULTIDISCPLLINAR \\ ISSN 1809-1628 HUMANIDADES E TECNOLOGIAS (FINOM)}

A população objeto deste estudo foi composta por coordenadores de curso de graduação que estão em atividades no segundo semestre do ano de 2021, em três instituições de ensino superior privadas, localizadas no estado de Minas Gerais. Para Silva (2007), em uma pesquisa científica a população é a coleção bem definida das unidades (sistemas) de interesse para a população qual é desejado inferir.

Coleta e análise de dados

A técnica de coleta de dados passa a ser um conjunto de regras ou processos utilizados por uma ciência, ou seja, corresponde à parte prática da coleta de dados (LAKATOS; MARCONI, 2001). Como instrumento de coleta de dados optou-se pela utilização de um questionário estruturado com a finalidade de se conhecer quais competências individuais, técnicas e comportamentais são consideradas relevantes pelo coordenador de curso para fazer o gerenciamento de suas funções. Marconi e Lakatos (1996, p. 88) definem o questionário estruturado como uma “[...] série ordenada de perguntas, respondidas por escrito sem a presença do pesquisador". O instrumento utilizado na coleta de dados consta no Anexo I.

O questionário foi estruturado em Escala Likert de 5 pontos (sem importância, pouco importante, importante, muito importante e imprescindível). Cunha (2007) descreve a escala tipo Likert como sendo aquela que é composta por um conjunto de frases (itens) em relação a cada uma das quais se pede ao sujeito que está a ser avaliado para manifestar o grau de concordância. A segmentação do questionário se deu em quatro etapas, com total de 17 perguntas, que tinham como base as funções definidas por Franco (2003). O autor distribui as funções dos coordenadores de curso em quatro áreas distintas: funções políticas, funções gerenciais, funções acadêmicas e funções institucionais. Foram realizados dois pré-testes para validação do questionário. No primeiro, o questionário foi respondido por dois coordenadores que não fazem parte da amostra selecionada para realização da pesquisa. Nesta etapa foram realizadas algumas alterações no instrumento, principalmente no que se refere às opções de respostas. O segundo pré-teste consistiu na validação do questionário por um estatístico e um técnico de tecnologia da informação, que não fazem parte da amostra selecionada para realização da pesquisa. $\mathrm{O}$ questionário foi enviado por meio de e-mail aos participantes e o 


\section{REVISTAMULTIDISCIPLINAR

período de coleta foi de 23/08/2021 a 28/08/2021, utilizando o Google Forms. Os respondentes indicaram o grau de importância para cada tópico abordado nas quatro etapas do questionário.

\section{Análise de resultados}

A análise e discussão dos resultados, contempla o roteiro da pesquisa, o que oportuniza a apresentação dos resultados, relacionados às características de liderança, comunicação, relacionamento interpessoal e empreendedorismo, que compõem as funções políticas.

Quadro I - Funções Políticas: Liderança, Comunicação, Relacionamento Interpessoal e Empreendedorismo

\begin{tabular}{|c|c|c|c|c|c|c|c|c|}
\hline \multicolumn{9}{|c|}{ I - Funções Políticas } \\
\hline \multirow[t]{2}{*}{ Resposta } & \multicolumn{2}{|c|}{ Liderança } & \multicolumn{2}{|c|}{$\begin{array}{c}\text { Comunicaçã } \\
\text { o }\end{array}$} & \multicolumn{2}{|c|}{$\begin{array}{c}\text { Relacionament } \\
\text { o } \\
\text { Interpessoal }\end{array}$} & \multicolumn{2}{|c|}{$\begin{array}{c}\text { Empreendedorism } \\
\text { o }\end{array}$} \\
\hline & $\mathbf{N}^{*}$ & $\%$ & $\mathbf{N}$ & $\%$ & $\mathbf{N}$ & $\%$ & $\mathbf{N}$ & $\%$ \\
\hline $\begin{array}{l}\text { Sem } \\
\text { importância }\end{array}$ & - & - & - & - & - & - & - & - \\
\hline $\begin{array}{l}\text { Pouco } \\
\text { importante }\end{array}$ & - & - & - & - & - & - & - & - \\
\hline Importante & 2 & 5,3 & - & - & - & - & 13 & 34,2 \\
\hline $\begin{array}{l}\text { Muito } \\
\text { importante }\end{array}$ & 17 & 44,7 & 3 & 7,9 & 18 & 47,4 & 12 & 31,6 \\
\hline $\begin{array}{l}\text { Imprescindíve } \\
1\end{array}$ & 19 & 50 & 35 & 92,1 & 20 & 52,6 & 13 & 34,2 \\
\hline Total & 38 & 100,0 & 38 & 100,0 & 38 & 100,0 & 38 & 100,0 \\
\hline
\end{tabular}

$\mathrm{N}$ : Número de observações

Fonte: Elaborado pelos autores com base nos dados da pesquisa

A pesquisa permite identificar, que as características de liderança e relacionamento interpessoal obtiveram resultados semelhantes, o que significa que os coordenadores consideram essas características como muito importantes para o exercício da função. Já quanto as características de empreendedorismo, passa a ser observada como sendo uma característica, menos importante. Entretanto, não ocorreu, para esta característica o 


\section{REVISTA MULTIDISCIPLINAR \\ ISSN 1809-1628 \\ HUMANIDADES E TECNOLOGIAS (FINOM)}

predomínio da resposta muito importante ou imprescindível, como ocorreu para as demais características.

Já para o exercício da função de coordenação de curso, os coordenadores consideram que é imprescindível possuir boa comunicação com todos os atores que estabelecem relação com as atividades exercidas.

No Quadro II estão apresentados os resultados da pesquisa relacionados às características de ensino, pesquisa/iniciação científica, extensão universitária, evasão e inadimplência, que compõem as funções gerenciais.

Quadro II - Funções Gerenciais: Ensino, Pesquisa/Iniciação Científica, Extensão Universitária, Evasão e Inadimplência

\begin{tabular}{|c|c|c|c|c|c|c|c|c|c|c|}
\hline \multicolumn{11}{|c|}{ II - Funções Gerenciais } \\
\hline \multirow[b]{2}{*}{ Resposta } & \multicolumn{2}{|c|}{ Ensino } & \multicolumn{2}{|c|}{$\begin{array}{l}\text { Pesquisa/ } \\
\text { Iniciação } \\
\text { Científica }\end{array}$} & \multicolumn{2}{|c|}{$\begin{array}{c}\text { Extensão } \\
\text { Universitária }\end{array}$} & \multicolumn{2}{|c|}{ Evasão } & \multicolumn{2}{|c|}{ Inadimplência } \\
\hline & $\mathbf{N *}$ & $\%$ & $\mathbf{N}$ & $\%$ & $\mathbf{N}$ & $\%$ & $\mathbf{N}$ & $\%$ & $\mathbf{N}$ & $\%$ \\
\hline $\begin{array}{l}\text { Sem } \\
\text { importância }\end{array}$ & - & - & - & - & - & - & - & - & 1 & 2,6 \\
\hline $\begin{array}{l}\text { Pouco } \\
\text { importante }\end{array}$ & - & - & - & - & - & - & - & - & 2 & 5,3 \\
\hline Importante & 1 & 2,6 & 2 & 5,3 & 3 & 7,9 & 3 & 7,9 & 14 & 36,8 \\
\hline $\begin{array}{l}\text { Muito } \\
\text { importante }\end{array}$ & 12 & 31,6 & 22 & 57,9 & 19 & 50 & 12 & 31,6 & 15 & 39,5 \\
\hline Imprescindíve & 25 & 65,8 & 14 & 36,8 & 16 & 42,1 & 23 & 60,5 & 6 & 15,8 \\
\hline Total & 38 & 100,0 & 38 & 100.0 & 38 & 100.0 & 38 & 100,0 & 38 & 100,0 \\
\hline
\end{tabular}

$\mathrm{N}$ : Número de observações

Fonte: Elaborado pelos autores com base nos dados da pesquisa

Para exercer a atividade de coordenação de curso, os respondentes consideram que é muito importante ou imprescindível atuar no ensino, pesquisa/iniciação científica e extensão. Destaca-se que consideraram, sobretudo, imprescindível atuar no ensino enquanto coordenadores de curso. Para além, os coordenadores de curso demonstraram, por meio de 


\section{REVISTAMULTIDISCIPLINAR \\ ISSN 1809-1628 HUMANIDADES E TECNOLOGIAS (FINOM)}

suas respostas, que o gestor deve-se preocupar consideravelmente com a evasão e também com a inadimplência, porém em menor magnitude.

A inadimplência merece atenção, por ser um tópico que interfere na evasão. Um dos fatores que leva a evasão é exatamente a inadimplência. De acordo com SEMESP (2019), a evasão deve-se a três fatores: decepção com a carreira escolhida, falta de condição financeira e falta de condição para acompanhar o ritmo das aulas, uma vez que, a grande maioria deste público trabalha durante o dia e estuda à noite.

A inadimplência é um dos itens de apresenta maior possibilidade de reversão, da decisão de abandono, porque a Instituições de Ensino Superior (IES) poderá negociar com o aluno a sua situação financeira e assim, reduzir os índices de evasão.

Franco (2003) enfatiza que o coordenador deve ser responsável pela adimplência contratual dos alunos de seu curso. Ainda, para o é indiscutível que tal matéria sempre é encarada com alguma reserva nas IES, especialmente pelos integrantes da área acadêmica.

No Quadro III estão apresentados os resultados da pesquisa relacionados ao envolvimento da coordenação de curso com o Projeto Pedagógico de Curso (PPC), Plano de Desenvolvimento Institucional (PDI) e Exame Nacional de Desempenho de Estudantes (ENADE), que compõem as funções acadêmicas.

Quadro III - Funções Acadêmicas: Projeto Pedagógico de Curso (PPC), Plano de Desenvolvimento Institucional (PDI) e Exame Nacional de Desempenho de Estudantes (ENADE).

\begin{tabular}{|c|c|c|c|c|c|c|}
\hline \multicolumn{7}{|c|}{ III - Funções Acadêmicas } \\
\hline \multirow[b]{2}{*}{ Resposta } & \multicolumn{2}{|c|}{$\begin{array}{c}\text { Projeto } \\
\text { Pedagógico de } \\
\text { Curso - PPC }\end{array}$} & \multicolumn{2}{|c|}{$\begin{array}{c}\text { Plano de } \\
\text { Desenvolvimento } \\
\text { Institucional - PDI }\end{array}$} & \multicolumn{2}{|c|}{$\begin{array}{c}\text { Exame Nacional de } \\
\text { Desempenho de } \\
\text { Estudantes - ENADE }\end{array}$} \\
\hline & $\mathbf{N}^{*}$ & $\%$ & $\mathbf{N}$ & $\%$ & $\mathbf{N}$ & $\%$ \\
\hline $\begin{array}{l}\text { Sem } \\
\text { importância }\end{array}$ & - & - & - & - & - & - \\
\hline $\begin{array}{l}\text { Pouco } \\
\text { importante }\end{array}$ & - & - & - & - & - & - \\
\hline Importante & 1 & 2,6 & 7 & 18,4 & 1 & 2,6 \\
\hline $\begin{array}{l}\text { Muito } \\
\text { importante }\end{array}$ & 5 & 13,2 & 14 & 36,8 & 8 & 21,1 \\
\hline Imprescindível & 32 & 84,2 & 17 & 44,7 & 29 & 76,3 \\
\hline Total & 38 & 100,0 & 38 & 100,0 & 38 & 100,0 \\
\hline
\end{tabular}

N: Número de observações 


\section{REVISTAMULTIDISCPLLNAR \\ ISSN 1809-1628 HUMANIDADES E TECNOLOGIAS (FINOM)}

Fonte: Elaborado pelos autores com base nos dados da pesquisa

Em relação às respostas para os elementos que compõem as funções acadêmicas, os entrevistados consideram imprescindível o envolvimento da coordenação de curso com o Projeto Pedagógico de Curso (PPC) e o Exame Nacional de Desempenho de Estudantes (ENADE). Já no que se refere ao Plano de Desenvolvimento Institucional (PDI), embora os coordenadores de curso apontaram ser, pelo menos, importante a sua participação na elaboração, implantação e revisão de tal documento, observa-se que é um elemento que não tem a mesma importância que os demais componentes das funções acadêmicas.

No Quadro IV estão apresentados os resultados da pesquisa relacionados ao envolvimento da coordenação de curso com a Comissão Própria de Avaliação (CPA), Políticas de Acompanhamento de Egressos, Fontes Alternativas de Recursos e Empregabilidade, que compõem as funções institucionais.

Quadro IV - Funções Institucionais: Comissão Própria de Avaliação (CPA), Política de Acompanhamento de Egressos, Fontes Alternativas de Recursos e Empregabilidade.

\begin{tabular}{|c|c|c|c|c|c|c|c|c|}
\hline \multirow[t]{2}{*}{ Resposta } & \multicolumn{2}{|c|}{$\begin{array}{c}\text { Comissão } \\
\text { Própria de } \\
\text { Avaliação - } \\
\text { CPA } \\
\end{array}$} & \multicolumn{2}{|c|}{$\begin{array}{c}\text { Políticas de } \\
\text { Acompanhamen } \\
\text { to de Egressos }\end{array}$} & \multicolumn{2}{|c|}{$\begin{array}{c}\text { Fontes } \\
\text { Alternativas } \\
\text { de Recursos }\end{array}$} & \multicolumn{2}{|c|}{$\begin{array}{l}\text { Empregabilida } \\
\text { de }\end{array}$} \\
\hline & $\mathbf{N}^{*}$ & $\%$ & $\mathbf{N}$ & $\%$ & $\mathbf{N}$ & $\%$ & $\mathbf{N}$ & $\%$ \\
\hline $\begin{array}{l}\text { Sem } \\
\text { importância }\end{array}$ & - & - & - & - & 1 & 2,6 & - & - \\
\hline $\begin{array}{l}\text { Pouco } \\
\text { importante }\end{array}$ & - & - & - & - & 1 & 2,6 & - & - \\
\hline Importante & 13 & 34,2 & 9 & 23,7 & 16 & 42,1 & 6 & 15,8 \\
\hline $\begin{array}{l}\text { Muito } \\
\text { importante }\end{array}$ & 17 & 44,7 & 16 & 42,1 & 14 & 36,8 & 18 & 47,4 \\
\hline${ }_{1}$ Imprescindíve & 8 & 21,1 & 13 & 34,2 & 6 & 15,8 & 14 & 36,8 \\
\hline Total & 38 & 100,0 & 38 & 100,0 & 38 & 100,0 & 38 & 100,0 \\
\hline
\end{tabular}

N: Número de observações

Fonte: Elaborado pelos autores com base nos dados da pesquisa

A maioria dos coordenadores que responderam à pesquisa consideram ser muito importante o envolvimento da coordenação de curso com a Comissão Própria de Avaliação (CPA), Política de Acompanhamento de Egressos e com a Empregabilidade dos alunos do curso. A resposta imprescindível foi a segunda mais apontada, pelos coordenadores de curso, quando se trata da Política de Acompanhamento de Egressos e a Empregabilidade. 


\section{REVISTAMULTIDISCIPLINAR \\ ISSN 1809-1628 HUMANIDADES E TECNOLOGIAS (FINOM)}

Para a maioria dos coordenadores de curso entrevistados a prospecção por fontes alternativas de recursos é importante no desenvolvimento de seu trabalho enquanto coordenador, porém, não é muito importante ou imprescindível.

É importante destacar que a participação do coordenador na busca por fontes de recursos financeiros alternativos merece atenção. Franco (2003) salienta que o coordenador de curso deve ser responsável pela busca de fontes alternativas de recursos. Contra os serviços prestados aos alunos, fixados em contrato, a IES recebe deles as mensalidades, que, infelizmente, não bastam. Fontes alternativas de recursos podem ser oriundas das mais diversas esferas da sociedade.

\section{Considerações}

O objetivo deste estudo foi o de compreender as competências individuais, técnicas e comportamentais consideradas relevantes pelo coordenador de curso para fazer o gerenciamento de suas funções. Assim, para além, do arcabouço teórico-metodológico, o estudo contou com um roteiro de pesquisa, que verifica o contexto acadêmico, no qual os docentes possuem maior interação diariamente, onde obtiveram um maior grau de pontuação por parte dos entrevistados. O coordenador de curso normalmente é um professor que já atua no curso, ou ainda, um pesquisador designado pela Instituição de Ensino Superior (IES) para coordenar as atividades acadêmicas do curso, já estando inserido, portanto em suas atividades algumas rotinas, tais como, ENADE, ciclos avaliativos da CPA, pesquisa/iniciação científica e extensão.

Desta forma a pesquisa identifica que as características de liderança e relacionamento interpessoal conquistaram bons resultados, o que indica para os coordenadores características muito importantes para o exercício da função. O mesmo valor não foi atribuído para as características de empreendedorismo, entendida como sendo menos importante. No entanto, a pesquisa aponta para o exercício da função de coordenação de curso, os coordenadores consideram que é imprescindível possuir boa comunicação com todos os atores que estabelecem relação com as atividades exercidas. 


\section{REVISTAMULTIDISCIPLINAR \\ ISSN 1809-1628 HUMANIDADES E TECNOLOGIAS (FINOM)}

O roteiro de pesquisa, que buscou compreender se é importante atuar no ensino, pesquisa/iniciação científica e extensão, aponta como resultado, que é imprescindível atuar no ensino, na qualidade de coordenador de curso. Ainda apontam que o gestor deve-se preocupar consideravelmente com a evasão, com a inadimplência, porém em menor magnitude.

Já a pesquisa que compõem as funções acadêmicas, os entrevistados apontaram imprescindível a presença da coordenação de curso com o Projeto Pedagógico de Curso e o Exame Nacional de Desempenho de Estudantes. Ainda a pesquisa identifica que maioria dos coordenadores consideram ser muito importante a presença da coordenação de curso com a Comissão Própria de Avaliação, na Política de Acompanhamento de Egressos e com a Empregabilidade dos alunos do curso.

Portanto, torna-se imprescindível que a IES tenha bem definido em sua descrição de cargos, qual é o escopo de atuação deste profissional, mantendo ciclos de feedback constantes, com o objetivo de que o profissional que venha atuar na coordenação de curso tenha condições de entender o alinhamento organizacional da instituição, o contexto social em que a mesma está inserida, bem como conheça as expectativas da IES, especialmente, a função de coordenação de curso. Um processo, em que a função, as atribuições necessitam estar bem alinhadas, mesmo que cada Instituição trilha suas atividades de maneira diferente, porém, a descrição do cargo necessita estar bem definida, para desenvolver as competências individuais, técnicas e comportamentais.

Por conseguinte, cabe as Instituições destinarem para as coordenações de cursos um horário, para além da sala de aula, para que esse profissional possa atuar junto aos alunos e professores, tendo Projeto Pedagógico Institucional e do curso, como linha mestra de seu trabalho, para ampliar sua visão sistêmica, para que consiga compreender a amplitude que seu trabalho, tanto no ambiente interno, como externo, que seja capaz de impulsionar docentes, discentes e técnicos-administrativos, por uma melhor qualidade de ensino.

\section{Referências}

AFFONSO, Ligia Maria, F. Teorias da administração. Disponível em: https://download.inep.gov.br/educacao_superior/avaliacao_cursos_graduacao/instrumentos/20 17/curso_autorizacao.pdf Acessado em maio de 2021 


\section{REVISTAMULTIDISCIPLINAR \\ ISSN 1809-1628 \\ HUMANIDADES E TECNOLOGIAS (FINOM)}

BAGGIO, Adelar Francisco; BAGGIO Daniel Knebel. Empreendedorismo: Conceitos e Definições.2014, Rev. de Empreendedorismo, Inovação e Tecnologia, disponível em: https://seer.imed.edu.br/index.php/revistasi/article/view/612/522 Acessado em maio de 2021

BINATTI, Roberta. A escola enquanto empresa prestadora de serviço. Disponível em: https://sites.google.com/site/agestaoeducacional/artigo/empresa. Acessado em agos. 2021

BRASIL. Portaria Normativa $\mathrm{n}^{0}$. 5, de 22 de fevereiro de 2010. Regulamentação dos procedimentos de avaliação do SINAES.

BRASIL. Lei de Diretrizes e Bases da Educação Nacional: Lei no 9.394, de 20 de dezembro de 1996, que estabelece as diretrizes e bases da educação nacional, 8. ed. Brasília: Câmara dos Deputados, Edições Câmara,2021.

CARBONELL, Jaume. Pedagogias do Século XXI. Disponível em: Minha Biblioteca, (3rd edição). Grupo A, 2016.

CUNHA, Luiza Margareth Antunes. Modelos Rasch e Escalas de Likert e Thurstone na medição de atitudes. 2007) Disponível em: https://repositorio.ul.pt/bitstream/10451/1229/1/18914_ULFC072532_TM.pdf. Acessado em $20 \mathrm{jul} / 2021$.

DELPINO, Rosemar; CANDIDO, Maria Lúcia Baltazar; MOTA, Ana Clara da, CAMPOS, Luciana: DEJUSTE, Maria Tereza. Ensino Superior: o novo perfil do coordenador de curso. 2009. XII Encontro Latino Americano de Iniciação Científica e VIII Encontro Latino Americano de Pós-Graduação - Universidade do Vale do Paraíba. Disponível em: http://www.inicepg.univap.br/cd/INIC_2008/anais/arquivosEPG/EPG00823_01_O.pdf

FERRARI, Fernanda Cristina; NASCIMENTO, Kelly Aparecida. Perfil dos coordenadores de cursos de uma Instituição de ensino superior. 2014, Revista Eletrônica da Faculdade Metodista Granbery. http://re.granbery.edu.br - ISSN 19810377

FRANCO, Maria Amélia Santoro. Coordenação pedagógica: uma práxis em busca de sua identidade. Revista Múltiplas Leituras, v. 1, n. 1, p. 117-131, jan/jun. 2008. Disponível em: <https://www.metodista.br/revistas/revistas-ims/index.php/ ML/article/viewFile/1176/1187. Acesso em: 20 julho. 2020

FRANCO, Edson Raymundo Pinheiro. Funções de um coordenador de cursos: como “ construir o coordenador ideal. ABMES, Brasília, 2003 Disponível em https://abmes.org.br/arquivos/publicacoes/ABMESCaderno8.pdf.Acessado em 07/07/2021

GIL, Carlos A. Como Elaborar Projetos de Pesquisa, 6a edição. Disponível em: Minha Biblioteca, Grupo GEN, 2017.

GRANEMANN, Ronaldo e ROCHA, Carlos Henrique. Gestão De Instituições Privadas De Ensino Superior. Disponível em: Minha Biblioteca, Grupo GEN, 2003. 


\section{REVISTAMULTIDISCPLLNAR \\ ISSN 1809-1628 \\ HUMANIDADES E TECNOLOGIAS (FINOM)}

HILSDORE, Maria Lúcia S. História da Educação Brasileira. Disponível emhttps://www.gov.br/inep/pt-br/acesso-a-informacao/dados-abertos/indicadoreseducacionais/indicadores-de-fluxo-da-educacao-superior Acessado em maio de 2021

LACOMBE, Francisco. Administração princípios e tendências. Disponível em: Minha Biblioteca, (3rd edição). Editora Saraiva, 2016.

MATIAS-PEREIRA. Manual de Metodologia da Pesquisa Científica. Disponível em: Minha Biblioteca, (4th edição). Grupo GEN, 2016.

MANÇO, Iracivan A. A pratica cotidiana do coordenador de curso superior privado e o tipo ideal Weberiano. 2016. Dissertação (Mestrado profissional em políticas públicas e gestão da Educação superior. Universidade Federal do Ceará - UFC

MARCON, S.R.A. Comportamentos que constituem o trabalho de coordenador de curso de graduação. 2008. Tese (Doutorado em Psicologia). Universidade Federal de Santa Catarina.

PESTANA, André. Gestão e educação: uma empresa chamada escola. Petrópolis, RJ: Catedral das letras, 2003.

PORTES, Écio, A. et al. História da Educação - Ensino e pesquisa. Disponível em: Minha Biblioteca, Grupo Autêntica, 2007.

RODRIGUES e BLIKSTEIN (Orgs.). Inovações Radicais na Educação Brasileira - Série: Tecnologia e Inovação na Educação Brasileira. Disponível em: Minha Biblioteca, Grupo A, 2019.

SAMPIERE, Roberto, H. et al. Metodologia de Pesquisa. Disponível em: Minha Biblioteca, (5th edição). Grupo A, 2013.

PORTO RÉGNIER. O Ensino Superior no Mundo e no Brasil - condicionantes, Tendências e Cenários para o Horizonte 2003-2025: Uma Abordagem Exploratória. Disponível em: http://portal.mec.gov.br/sesu/arquivos/pdf/ensinosuperiormundobrasiltendenciascenarios2003 -2025.pdf Acessado em maio de 2021.

ZAMBERLAN, L C; SOUZA， J. D. S. de; GRISON， A. J.; GAGLIARDI， A. de O.; TEXEIRA， E. B.; DREWS， G. A.; VIEIRA， E. P.; BRIZOLLA, M. M. B.; ALLEBRANDT, S. L. Pesquisa em ciências sociais aplicadas. Ijuí: Ed. Unijuí, 2014 